\title{
ANALISIS KUALITAS PRODUK, HARGA, KUALITAS PELAYANAN YANG MEMPENGARUHI KEPUASAN KONSUMEN DALAM PEMBELIAN PRODUK KEDAI ORGANIK KOLONDJONO, CONDONGCATUR, YOGYAKARTA
}

\author{
Analysis of Product Quality, Price, Service Quality That Influence Custumers \\ Satisfaction In Purchasing product Kedai Organik Kolondjono, Condongcatur, \\ Yogyakarta
}

\author{
Ramos Mitrand Gultom*, Budiarto, Heni Handri Utami \\ Program Studi Agribisnis Jurusan Agribisnis Fakultas Pertanian \\ Universitas Pembangunan Nasional "Veteran" Yogyakarta \\ Jl. SWK 104 (Lingkar Utara) Condongcatur Yogyakarta Indonesia 55283 \\ email korespondensi : ramosmitrand@gmail.com
}

Diterima tanggal : 5 Agustus 2019 ; Disetujui tanggal : 23 Oktober 2019

\begin{abstract}
This research aimed to: 1) Analyzed the influence of product quality, price and service quality factors on consumer satisfaction at Kedai Organik Kolondjono 2) Analyzed the compatibility between the performance of Kedai Organik Kolondjono and importance of consumers 3) Analyzed indicators of product quality, price and service quality which are the top priority of improvement to increase customer satisfaction based on Importence Performance Analysis (IPA) with Cartesian diagram. This research used descriptive method, the method of conducting research used survey methods and the determination of respondents by accidental sampling method. Types of data used in the form of primary data and secondary data. Data collection techniques used questionnaires observation, interviews, and documentation. The analysis technique used multiple linear regression analysis, and Importance Performance Analysis (IPA). The results of the study, it can be concluded that: 1) Product quality, price and service quality influence consumer satisfaction at Kedai Organik Kolondjono 2) Overall the performance of the Kedai Organik Kolondjono was smaller than the interests of consumers. That was not all the interests of consumers met 3) Indicators that become the main priority for improvement are varied menus, price and quality suitability, price affordability, service accuracy, speed, accuracy of service, friendliness of the waiter and the level of concern of the waiter.
\end{abstract}

Keywords: Customer Satisfaction, Price, Product Quality, Service Quality

\begin{abstract}
ABSTRAK
Penelitian ini bertujuan untuk: 1) Menganalisis pengaruh faktor kualitas produk, harga dan kualitas pelayanan terhadap kepuasan konsumen Kedai Organik Kolondjono 2) Menganalisis kesesuaian antara kinerja (performance) Kedai Organik Kolondjono dan kepentingan (importence) konsumen
\end{abstract}


3) Menganalisis indikator kualitas produk, harga dan kualitas pelayanan yang menjadi prioritas utama perbaikan untuk meningkatkan kepuasan konsumen berdasarkan Importence Performance Analysis (IPA) dengan diagram kartesius. Penelitian ini menggunakan metode deskriptif, metode pelaksanaan penelitian menggunakan metode survei dan penentuan responden dengan metode accidental sampling. Macam data yang digunakan berupa data primer dan data sekunder. Teknik pengumpulan data menggunakan kuisioner (angket), observasi, wawancara, dan dokumentasi. Teknik analisis yang digunakan adalah analisis Regresi Linear Berganda, dan Importance Performance Analysis (IPA). Berdasarkan hasil penelitian, dapat disimpulkan bahwa: 1) Kualitas produk, harga dan kualitas pelayanan berpengaruh terhadap kepuasan konsumen Kedai Organik Kolondjono 2) Secara keseluruhan kinerja Kedai Organik Kolondjono lebih kecil dari kepentingan konsumen. Artinya, kepentingan konsumen belum semuanya terpenuhi 3) Indikator yang menjadi prioritas utama perbaikan adalah menu yang bervariasi, kesesuaian harga dan kualitas, keterjangkauan harga, keakuratan pelayanan, kecepatan, ketepatan pelayanan, keramahan pelayan dan tingkat kepedulian pelayan.

Kata Kunci : Kepuasan Konsumen, Harga, Kualitas Produk, Kualitas Pelayanan

\section{PENDAHULUAN}

Yogyakarta dikenal sebagai kota pendidikan, kota pelajar, kota budaya dan wisata. Hal ini menjadi pendukung bagi pengusaha untuk membuka usaha bisnisnya di Yogyakarta. Bisnis yang berkembang pesat ialah bisnis makanan atau dikenal dengan bisnis kuliner. Munculnya kesadaran masyarakat akan bahaya kandungan zat kimia pada makanan membuat masyarakat menjadi lebih selektif dalam memilih suatu produk terlebih produk yang ingin dikonsumsi. Oleh karena itu, akhir-akhir ini banyak muncul berbagai produk pertanian di pasaran bahkan supermarket seperti sayur dan buah organik. Di Yogyakarta terdapat beberapa rumah makan organik diantaranya yaitu, Milas Resto, Mie Pelangi 88, Warung Nasi Bakar Organik GJR, Warung Somayoga, dan Kedai Organik Kolondjono. Kedai Organik Kolondjono merupakan salah satu rumah makan yang mengolah produk-produk organik menjadi makanan yang sehat bagi konsumen.

Bahan baku yang digunakan untuk disajikan berasal dari produk organik. Produk organik adalah produk yang di dapat tanpa ada penggunaan bahan-bahan sintetik, tidak ada modifikasi genetik, tidak menghasilkan limbah dan tidak ada radiasi. Makanan dan minuman yang berasal dari produk organik tentu besar manfaatnya bagi kesehatan tubuh manusia. Tubuh kita akan lebih mudah 
bermetabolisme, daya tahan dan kebugaran terjaga, dan mencegah obesitas. Pada saat penulis mencoba untuk membeli beberapa produk Kedai Organik Kolondjono, kualitas produk yang diberikan dari segi tampilan penelitian terlihat mewah, aromanya yang menggugah selera, serta cita rasa yang cukup memuaskan. Walaupun namanya Kedai Organik Kolondjono, namun produk yang ditawarkan tidak berasal sepenuhnya dari bahan organik.

Harga produk Kedai Organik Kolondjono tergolong memiliki harga yang lebih mahal dibandingkan dengan pesaing, hal ini dikarenakan bahan baku yang berkualitas dan penyajiannya lebih menarik dan memiliki nilai lebih yang didapatkan. Kedai Organik Kolondjono menetapkan harga makananan dimulai dari Rp 22.000,00 - Rp 32.000,00. Untuk minuman dimulai dari Rp 15.000,00 Rp 30.000,00. Dan untuk makanan penutup (pudding) sebesar Rp 6.000,00. Dalam sehari konsumen yang membeli bisa mencapai 10-20 orang. Untuk kualitas pelayanan, penulis menilai kualitas pelayanan yang diberikan kurang bagus, dikarenakan lama nya pesanan datang.

Kedai Organik Kolondjono memiliki konsumen tetap. Hal inilah yang menyebabkan penulis bertanya-tanya kenapa usaha, dengan harga produk yang cukup mahal, lamanya pesanan datang, tetapi memiliki konsumen tetap. Berdasarkan latar belakang tersebut, tujuan dari penelitian ini adalah mengetahui pengaruh harga, kualitas produk dan pelayanan terhadap tingkat kepuasan konsumen di Kedai Organik Kolondjono.

\section{METODE PENELITIAN}

Metode dasar yang digunakan dalam penelitian ini adalah metode deskrpitif analisis, yaitu metode yang digunakan untuk mencari unsur-unsur, ciriciri, sifat suatu fenomena dengan cara mengumpulkan data, menganalisis dan menginterpretasikannya (Mulyadi, 2012) Metode pelaksanaan penelitian yang digunakan dalam penelitian ini yaitu metode survei. Metode pemilihan lokasi dengan metode purposive sampling, yaitu suatu metode penentuan lokasi secara sengaja melalui berbagai pertimbangan. Lokasi yang penulis pilih adalah Kedai Organik Kolondjono, karena Kedai Organik Kolondjono menyediakan makanan 
organik berbahan dasar nabati dan hewani. Metode penentuan responden menggunakan, accidental sampling, yaitu teknik penentuan responden berdasarkan kebetulan karena konsumen Kedai Organik Kolondjono tidak diketahui secara pasti (Sugiyono, 2016)

Data yang digunakan dalam penelitian merupakan data primer yaitu data penilaian konsumen pada kualitas produk, harga dan kualiatas pelayanan terhadap kepuasan konsumen di Kedai Organik Kolondjono dan data sekunder yaitu daftar harga produk Kedai Organik Kolondjono, dan hasil penelitian yang sudah diolah. Metode pengumpulan data menggunakan kuisioner (angket), observasi, wawancara dan dokumentasi. Teknik analisis dan pengujian hipotesis menggunakan Regresi Linear Berganda untuk mengetahui pengaruh kualitas produk, harga dan kualitas pelayanan terhadap kepuasan konsumen dan Importence Performance Analysis (IPA) untuk mengetahui tingkat kesesuaian antara kinerja Kedai Organik Kolondjono dan kepentingan konsumen dan mengetahui indikator yang menjadi perbaikan utama untuk meningkatkan kepuasan konsumen.

\section{Analisis Regresi Linear Berganda}

Teknik analisis dan pengujian hipotesis yang digunakan ialah Analisis Regresi Linear Berganda. Analisis regresi linear berganda menunjukkan arah hubungan antara variable dependen dengan variable independen (Ghozali, 2013) dimana variable dependen (kepuasan konsumen), dan variable independen (kualiatas produk, kualitas pelayanan, dan harga). Persamaan regresi linear berganda dapat dilihat pada Persamaan (1).

$\mathrm{Y}=\mathrm{a}+\mathrm{b}_{1} \mathrm{X}_{1}+\mathrm{b}_{2} \mathrm{X}_{2}+\mathrm{b}_{3} \mathrm{X}_{3}+\mathrm{e}$

Keterangan:

Y : Kepuasan Konsumen (Skor)

a : Konstana

$\mathrm{X}_{1} \quad$ : Kualitas Produk (Skor)

$\mathrm{X}_{2} \quad$ : Harga(Skor)

$\mathrm{X}_{3} \quad$ : Kualitas Pelayanan (Skor)

e : Kesalahan Pengganggu

$\mathrm{b}_{1}, \mathrm{~b}_{2}, \mathrm{~b}_{3}$ : Koefisien regresi 
Menurut Herlawati (2015), uji koefisien determinasi dilakukan untuk mengetahui kecepatan model yang digunakan nilai koefisien yang terletak antar nol dan satu $\left(0<R^{2}<1\right)$. Model dianggap baik jika $R^{2}$ mendekati 1 . Jika $\mathrm{R}=0$ maka diantara variabel bebas dengan variabel terikat tidak ada hubungan. Nilai $R^{2}$ dihitung dengan menggunakan Persamaan (2).

$R^{2}=\frac{\text { ESS }}{T S S}=\frac{\Sigma(Y i-\gamma){ }^{2}}{\Sigma(Y i-\gamma)}$

Keterangan :

$R^{2}$ : Koefisien determinasi

ESS : Jumlah kuadrat yang dijelaskan

TSS : Jumlah kuadrat total

Uji F dilakukan untuk mengetahui ada tidaknya hubungan atau pengaruh nyata semua variabel independen (X) secara bersama sama terhadap variabel dependen (Y). Tingkat kesalahan (e) yang digunakan adalah 0,05. Menurut Ghozali (2013), persamaan uji F dapat dilihat pada Persamaaan (3).

$\mathrm{Fh}=\frac{R^{2} / k}{\left[\left(1-R^{2}\right)(n-k-1)\right]}$

Keterangan :

Fh : F hitung yang selanjutnya dibandingkan dengan $\mathrm{F}$ tabel

$R^{2} \quad$ : Koefisien determinasi

$k \quad$ : Jumlah variabel bebas (X)

$n \quad$ : Jumlah sampel

Uji $\mathrm{t}$ dilakukan untuk menguji pengaruh masing masing variabel independen $(\mathrm{X})$ berpengaruh terhadap variabel dependen(Y). Persamaan uji t dapat dilihat pada Persamaan (4).

$\mathrm{t}=\frac{X-\mu 0}{\frac{s}{\sqrt{n}}}$

Keterangan:

$\mathrm{t} \quad$ : Nilai $\mathrm{t}$ dihitung

$\mathrm{X}$ : Nilai rata-rata

нo : Nilai yang dihipotesiskan

S : Standart deviasi sampel

$\mathrm{n}$ : Jumlah anggota responden 


\section{Importence Performane Analysis (IPA)}

Metode Importence Performance Analysis (IPA) merupakan metode yang mengaitkan antara tingkat kepentingan (importence) suatu atribut yang dimiliki oleh suatu produk tertentu dengan kenyataan (performance) yang dirasakan oleh konsumen. Untuk menjelaskan tingkat kepentingan digunakan skala Likert, yaitu dengan intensitas paling rendah diberi angka satu (sangat tidak penting) sampai paling tinggi diberi angka lima (sangat penting). Begitupun dengan tingkat kinerja, penjelasannya menggunakan skala Likert dengan intensitas paling rendah diberi angka satu (sangat tidak puas) sampai paling tinggi diberi angka lima (sangat puas). Penilaian tingkat kinerja diwakili oleh huruf $\mathrm{X}$, sedangkan untuk penilaian tingkat kepentingan diwakili oleh huruf Y (Hifadri, 2016).

Menghitung rata-rata tingkat kinerja dan tingkat kepentingan untuk setiap item dari atribut dengan Persamaan (5).

$\bar{X}=\frac{\sum X i}{n}$ dan $\bar{Y}=\frac{\sum Y i}{n}$

Keterangan :

$\bar{X}$ : skor rata-rata tingkat kinerja atribut ke-i

$\bar{Y} i$ : skor rata-rata tingkat kepentingan atribut ke-i

$\mathrm{n}$ : jumlah responden

Menghitung rata-rata tingkat kinerja dan tingkat kepentingan untuk keseluruhan atribut dengan Persamaan (6).

$\overline{\bar{X}}=\frac{\sum \mathrm{i} \bar{X} i}{\mathrm{p}} \operatorname{dan} \overline{\bar{Y}}=\frac{\sum \mathrm{i} \overline{Y_{l}}}{\mathrm{p}}$

Keterangan:

$\overline{X l}:$ nilai rata-rata tingkat kinerja

$\bar{Y}_{i}$ : nilai rata-rata tingkat kepentingan

$\mathrm{p} \quad$ : jumlah atribut

Jika skor rata-rata tingkat kinerja lebih besar atau sama dengan skor ratarata tingkat kepentingan maka kinerja suatu produk telah memenuhi harapan dari konsumen. Jika skor rata-rata tingkat kinerja lebih kecil dari skor rata-rata tingkat kepentingan maka kinerja dari atribut-atribut produk tersebut masih belum bisa memenuhi harapan konsumen. 
Untuk mencari tingkat kesesuaian, maka skor rata-rata kinerja dibagi skor rata-rata kepentingan dikali 100\% yang dirumuskan melalui Persamaan (7)

$\mathrm{Tki}=\frac{\bar{X} i}{\overline{Y_{l}}} \times 100 \%$

Keterangan:

Tki : Tingkat kesesuaian responden

$\bar{X} i \quad$ : Skor rata-rata penilaian pelaksanaan/ kinerja perusahaan

$\overline{Y_{l}} \quad$ : Skor rata-rata penilaian kepentingan konsumen

Untuk mencari total tingkat kesesuaian, maka skor total kinerja dibagi skor total kepentingan dikali 100\% yang dirumuskan melalui Persamaan (8).

Tki Total $=\frac{\sum \bar{X}}{\sum \bar{Y}} \times 100 \%$

Keterangan:

Tki Total : Total tingkat kesesuaian responden

$\sum \bar{X} \quad$ : Total skor rata-rata penilaian kinerja perusahaan

$\sum Y$ : Total skor rata-rata penilaian kepentingan konsumen

Langkah yang terakhir adalah tingkat kinerja dan kepentingan atribut tersebut akan dijabarkan dan diplotkan ke dalam empat bagian pada diagram kartesius, yaitu kuadran I, II, III, dan IV. Hubungan antara tingkat kinerja (X) atau performance dan tingkat kepentingan $(\mathrm{Y})$ atau importence yang diperoleh dari responden juga dapat diinterpretasikan oleh Diagram Kartesius Importence Performance Analysis (IPA) yang ditunjukkan pada Gambar. 1

\begin{tabular}{c|c|c} 
High & $\begin{array}{c}\text { Quadrant I Attributes } \\
\text { to Improves }\end{array}$ & $\begin{array}{c}\text { Quadrant II Maintance } \\
\text { Performances }\end{array}$ \\
\cline { 2 - 3 } Low & $\begin{array}{c}\text { Quadrant III } \\
\text { Attributes Maintance }\end{array}$ & to deemphasize \\
\cline { 2 - 2 } & \multicolumn{2}{|c}{ Low Performance (X) High IV Attributes }
\end{tabular}

Gambar 1. Diagram Kartesius Importence Performance Analysis (IPA) Sumber : Suhendra (2016) 
Kuadran I (Attributes to Improve) merupakan wilayah yang atributatributnya dianggap penting oleh pelanggan tetapi pada kenyataannya atributatribut tersebut belum sesuai seperti yang diharapkan oleh pelanggan. Atribut yang masuk ke dalam kuadran ini harus segera ditingkatkan dan memiliki prioritas tinggi. Kuadran II (Maintain Performance), memuat atribut-atribut yang dianggap penting oleh pelanggan dan kinerja dari masing-masing atribut tersebut sudah sesuai dengan yang dirasakan oleh pelanggan sehingga tingkat kepuasannya relatif lebih tinggi. Atribut-atribut yang masuk ke dalam kuadran ini harus tetap dipertahankan. Kuadran III (Attributes to Maintain) memuat atribut-atribut yang dianggap kurang penting oleh pelanggan dan pada kenyatannya kinerjanya tidak terlalu istimewa dan memiliki prioritas rendah. Kuadran IV (Attributes to Deemphasize), dianggap tidak terlalu penting oleh konsumen, tetapi telah dijalankan dengan sangat baik oleh perusahaan dan dianggap berlebihan.

\section{HASIL DAN PEMBAHASAN}

\section{Pengaruh Faktor Kualitas Produk, Harga Kualitas Pelayanan Terhadap Kepuasan Konsumen}

Analisis regresi linear berganda digunakan untuk mengetahui pengaruh kualitas produk, harga, kualitas pelayanan terhadap kepuasan konsumen di Kedai Organik Kolondjono. Pada pengujian hipotesis ini, data penelitian dianalisis menggunakan program SPSS. Faktor-faktor yang berpengaruh terhadap kepuasan konsumen di Kedai Organik Kolondjono dapat dilihat pada Tabel. 1

Tabel 1. Hasil Analisis Regresi Linear Berganda

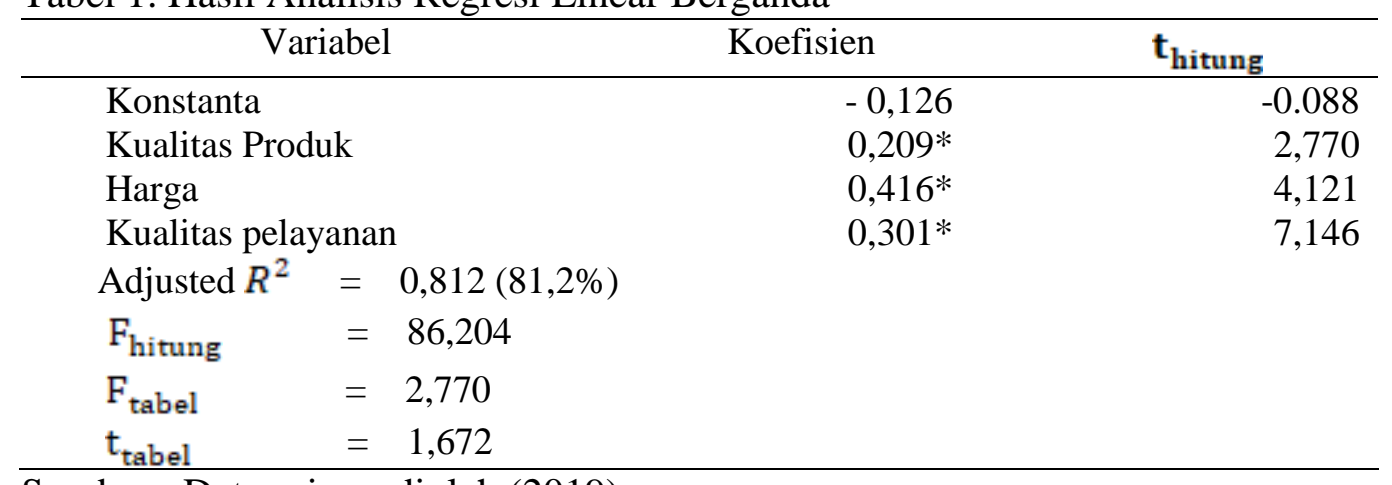

Sumber : Data primer diolah (2019)

Keterangan (*) : Signifikan pada $\alpha=5 \%=0,05$ 
Berdasarkan Tabel. 1, dapat dituliskan rumus persamaan hasil analisis regresi linear berganda pada Persamaan (9).

$\mathrm{Y}=-0,126+0,209 \mathrm{X}_{1}+0,416 \mathrm{X}_{2}+0,301 \mathrm{X}_{3}+\mathrm{e}$

Nilai koefisien determinasi (Adjusted $\mathrm{R}^{2}$ ) $=0,812$, dari hasil tersebut dapat dijelaskan bahwa sumbangan pengaruh kualitas produk, harga dan kualitas pelayanan menjelaskan varians kepuasan konsumen sebesar 81,2\%, dan ada sebesar 18,8\% varians dari kepuasan konsumen dijelaskan oleh faktor lain yang tidak diteliti.

Dalam pengujian $\mathrm{F}$ statistik menunjukkan dengan tingkat signifikan 5\% diperoleh nilai $\mathrm{F}_{\text {hitung }}>\mathrm{F}_{\text {tabel }}$ yaitu 86,204 > 2,770, maka Ha diterima dan Ho ditolak, hasil tersebut dapat dijelaskan bahwa variabel kualitas produk, harga dan kualitas pelayanan berpengaruh secara bersama-sama terhadap kepuasan konsumen di Kedai Organik Kolondjono.

Uji t variabel kualitas produk $\left(\mathrm{X}_{1}\right)$ terhadap kepuasan konsumen (Y) dengan taraf $\alpha=5 \%=0,05$ dan hasil olah data diperoleh nilai $\mathrm{t}_{\text {hitung }}=2,770>$ $\mathrm{t}_{\text {tabel }}=1,672$, maka Ha diterima atau Ho ditolak, dapat disimpulkan bahwa kualitas produk berpengaruh terhadap kepuasan konsumen secara parsial serta mempunyai hubungan searah. Hal ini didukung dengan penelitian Indrajaya (2016) yang mengatakan bahwa kualitas produk memiliki hubungan yang searah. Hal ini mengandung arti bahwa semakin meningkat kualitas produk maka semakin meningkat juga kepuasan konsumen. Uji t variabel harga $\left(\mathrm{X}_{2}\right)$ terhadap kepuasan konsumen (Y) dengan taraf nyata $\alpha=5 \%=0,05$ dan berdasarkan hasil olah data diperoleh nilai $\mathrm{t}_{\text {litung }}=4,121>\mathrm{t}_{\text {tabel }}=1,672$, maka Ha diterima atau Ho ditolak, dapat disimpulkan bahwa harga berpengaruh terhadap kepuasan konsumen secara parsial dan mempunyai hubungan searah.

Hal ini didukung dengan penelitian Purnamasari (2015) yang mengatakan bahwa harga memiliki hubungan yang searah terhadap kepuasan konsumen. Hasil tersebut menunjukkan bahwa setiap kenaikan variabel harga maka kepuasan konsumen akan cenderung naik. Menurut Asri (2010) penilaian harga dapat memberikan pengaruh yang besar bagi konsumen untuk memilih produk tertentu maupun toko atau penjual tertentu. Semakin tinggi nilai atau manfaat yang 
dirasakan seseorang dari produk tersebut maka semakin tinggi nilai tukar produk tersebut dimatanya dan semakin besar pula alat penukar yang bersedia dikorbankan. Nilai atau manfaat yang dirasakan konsumen berupa mengkonsumsi makanan berbahan dasar organik yang berguna bagi kesehatan konsumen.

Uji t variabel kualitas pelayanan $\left(\mathrm{X}_{3}\right)$ terhadap kepuasan konsumen $(\mathrm{Y})$ dengan taraf nyata $\alpha=5 \%=0,05$ dan berdasarkan hasil olah data diperoleh nilai $\mathrm{t}_{\text {hitung }}=7,146>\mathrm{t}_{\text {tabel }}=1,672$, maka Ha diterima atau Ho ditolak, dan dapat disimpulkan bahwa kualitas pelayanan berpengaruh terhadap kepuasan konsumen secara parsial dan mempunyai hubungan searah. Hal ini didukung dengan penelitian Lumintang, et.al., (2018) yang mengatakan bahwa kualitas pelayanan memiliki hubungan yang searah dengan kepuasan konsumen. Hal ini mengandung arti bahwa semakin meningkat kualitas pelayanan maka, semakin meningkat juga kepuasan konsumen.

\section{Kesesuaian Kinerja (Performance) Kedai Organik Kolondjono dan Kepentingan (Importence) Konsumen}

Dari 60 responden konsumen Kedai Organik Kolondjono diperoleh tingkat kesesuaian dari dimensi kualitas produk, harga dan kualitas pelayanan berdasarkan jawaban yang diberikan oleh konsumen melalui kuisioner. Total tingkat kesesuaian kinerja Kedai Organik Kolondjono lebih kecil dari kepentingan konsumen, artinya kepentingan konsumen belum semuanya terpenuhi. Hal ini dapat dilihat melalui Tabel. 2

Tabel 2. Tingkat Kesesuaian Kinerja Perusahaan dan Kepentingan Konsumen Terhadap Kualitas Produk, Harga dan Kualitas Pelayanan

\begin{tabular}{lrrr}
\hline \multicolumn{1}{c}{ Indikator } & $\begin{array}{c}\text { Rata-rata } \\
\text { Kinerja }\end{array}$ & $\begin{array}{c}\text { Rata-rata } \\
\text { Kepentingan }\end{array}$ & $\begin{array}{c}\text { Kesesuaian } \\
(\%)\end{array}$ \\
\hline Kualitas Produk & & & \\
Menu yang bervariasi & 4,05 & 4,30 & 94,18 \\
Kualitas rasa & 4,46 & 4,53 & 98,45 \\
Banyaknya porsi & 4,23 & 3,93 & 107,63 \\
Ketersediaan menu & 4,38 & 4,11 & 106,56 \\
Tampilan produk & 4,46 & 4,46 & 100,00 \\
Harga & & & \\
Kesesuaian harga dengan kualitas & 4,01 & 4,36 & 91,97 \\
\hline
\end{tabular}


Gultom et.al. / Jurnal Dinamika Sosial Ekonomi Vol.20 No.2, Desember 2019

\begin{tabular}{|c|c|c|c|}
\hline Indikator & $\begin{array}{l}\text { Rata-rata } \\
\text { Kinerja }\end{array}$ & $\begin{array}{l}\text { Rata-rata } \\
\text { Kepentingan }\end{array}$ & $\begin{array}{l}\text { Kesesuaian } \\
(\%)\end{array}$ \\
\hline Nilai produk & 3,85 & 3,51 & 109,68 \\
\hline Keterjangkauan harga & 3,43 & 4,31 & 79,58 \\
\hline \multicolumn{4}{|l|}{ Kualitas Pelayanan } \\
\hline Kelengkapan fasilitas fisik & 4,13 & 4,06 & 101,72 \\
\hline Kebersihan lingkungan & 4,35 & 4,68 & 92,94 \\
\hline Penampilan pelayan & 4,20 & 3,91 & 107,41 \\
\hline Keakuratan pelayanan & 4,08 & 4,26 & 95,77 \\
\hline Kecepatan, ketepatan pelayanan & 3,78 & 4,36 & 86,69 \\
\hline Keramahan pelayan & 4,05 & 4,25 & 95,29 \\
\hline $\begin{array}{l}\text { Pengetahuan pelayan secara } \\
\text { keseluruhan }\end{array}$ & 4,20 & 4,01 & 104,73 \\
\hline $\begin{array}{l}\text { Kepercayaan konsumen terhadap } \\
\text { pelayan }\end{array}$ & 4,28 & 4,03 & 106,20 \\
\hline Tingkat kepedulian pelayan & 4,06 & 4,46 & 91,03 \\
\hline Jumlah & 4,07 & 4,18 & 97,36 \\
\hline
\end{tabular}

Sumber: Data primer diolah (2019)

Indikator Kualitas Produk, Harga, Kualitas Pelayanan Yang Menjadi Prioritas Utama Perbaikan

Berdasarkan diagram kartesius, indikator kualitas produk, harga dan kualitas pelayanan yang dianalisis tersebar menjadi empat bagian yaitu kuadran I (prioritas utama), kuadran II (pertahankan prestasi), kuadran III (prioritas rendah) dan kuadran IV (berlebihan). Hal ini dapat dilihat pada Gambar. 2

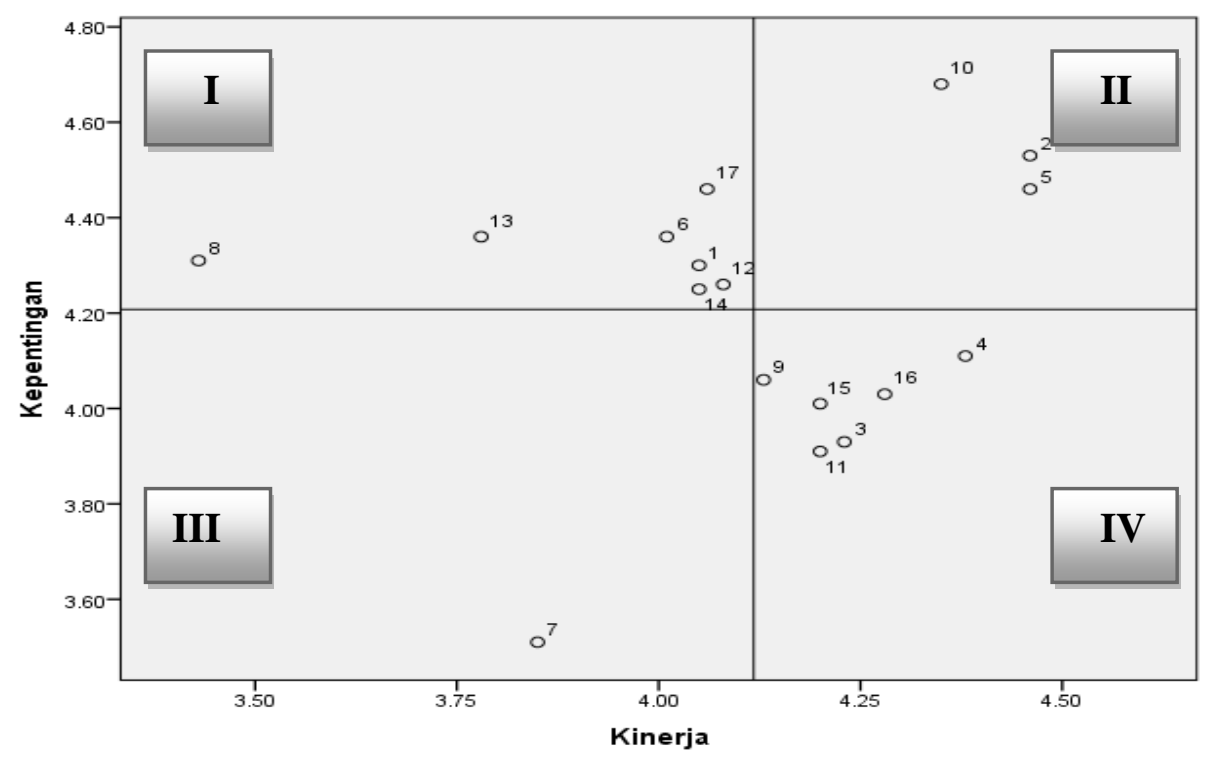

Gambar 2. Diagram Kartesius Importence Performane Analysis (IPA)

Sumber : Data primer diolah (2019) 
Keterangan:

1. Menu yang bervariasi

2. Kualitas rasa

3. Banyaknya porsi

4. Ketersediaan menu

5. Tampilan produk

6. Kesesuaian harga dengan kualitas

7. Nilai produk

8. Keterjangkauan harga

9. Kelengkapan fasilitas fisik

10. Kebersihan lingkungan

11. Penampilan pelayan

12. Keakuratan pelayanan

13. Kecepatan, ketepatan pelayanan

14. Keramahan pelayan

15. Pengetahuan pelayan secara keseluruhan

16. Kepercayaan konsumen terhadap pelayan

17. Tingkat kepedulian pelayan

Kuadran I terdapat 7 indikator, yaitu menu yang bervariasi, kesesuaian harga dan kualitas, keterjangkauan harga, keakuratan pelayanan, kecepatan, ketepatan pelayanan, keramahan pelayan, tingkat kepedulian pelayan. Kuadran II terdapat 3 indikator, yaitu kualitas rasa, tampilan produk, kebersihan lingkungan. Kuadran III hanya terdapat 1 indikator, yaitu nilai produk. Kuadran IV terdapat 6 indikator, yaitu banyaknya porsi, ketersediaan menu, kelengkapan fasilitas fisik, penampilan pelayan, pengetahuan pelayan secara keseluruhan, kepercayaan konsumen terhadap pelayan.

\section{KESIMPULAN DAN SARAN}

\section{Kesimpulan}

Berdasarkan analisis yang dilakukan, dapat disimpulkan bahwa kualitas produk, harga dan kualitas pelayanan berpengaruh terhadap kepuasan konsumen Kedai Organik Kolondjono. Total tingkat kesesuaian kinerja Kedai Organik Kolondjono lebih kecil dari kepentingan konsumen, artinya kepentingan konsumen belum semuanya terpenuhi. Indikator yang menjadi prioritas utama perbaikan adalah menu yang bervariasi, kesesuaian harga dan kualitas, 
keterjangkauan harga, keakuratan pelayanan, kecepatan, ketepatan pelayanan dan tingkat kepedulian pelayan.

\section{Saran}

Pada variabel kualitas produk, prioritas utama yang harus diperbaiki ialah menu yang bervariasi terutama pada produk fish katsu sambal matah. Variasinya bisa ditambahkan dengan berbagai macam produk ikan seperti ikan dori. Variasi juga bisa ditambahkan dengan berbagai macam sambal misalnya, sambal bawang, kecap, korek, teri, matang, cabe ijo, dan lain-lain. Mempertahankan kualitas rasa dan tampilan produk. Pada variabel harga, prioritas utama yang harus diperbaiki adalah kesesuaian harga dan kualitas, dan keterjangkauan harga dengan cara menyesuaikan harga dengan pesaing sejenis dan saran konsumen yaitu harga dibawah Rp 25.000,00 per porsi. Pada variabel kualitas pelayanan, prioritas utama yang harus di perbaiki ialah keakuratan pelayanan, kecepatan dan ketepatan pelayanan, keramahan pelayan, tingkat kepedulian pelayan dengan cara memberikan pelatihan kepada semua pelayan.

\section{UCAPAN TERIMAKASIH}

Ucapan terimakasih diberikan kepada Lembaga Penelitian dan Pengabdian Kepada Masyarakat (LPPM) Universitas Pembangunan Nasional "Veteran" Yogyakarta atas bantuan dana dalam penelitian dan penulisan karya ilmiah ini.

\section{DAFTAR PUSTAKA}

Asri, Marwan. (2010). Marketing. Yogyakarta : Unit Penerbit dan Percetakan AMP YKPN

Ghozali, Imam. (2013). Aplikasi Analisis Multivariate dengan Program IBM SPSS 21 Update PLS Regresi. Semarang: Badan Penerbit Universitas Diponegoro

Herlawati, Poppy. (2015). Metode Regresi Linear Berganda Kualita Super Member Supermall Terhadap Peningkatan Jumlah Pengunjung Pada Supermall Karawang. Bina Insani ICT Journal, 2 (2), 103, 2355-3421.

Hifadri, (2016). Analisis Kepuasan Konsumen Mienampol. Skripsi. IPB

Indrajaya, Sonny. (2016). Analisa Pengaruh Kemudahan Belanja, Kualitas Produk Belanja di Toko Online. Neliti Jurnal Ilmu Ekonomi dan Sosial, 5 (2), 134-141.

Lumintang, Joyce, Merlyn. (2018). Pengaruh Harga dan Kualitas Layanan 
Terhadap Kepuasan Pelanggan Jasa Transportasi Go-Jek Online Pada Mahasiswa FEB Unsrat Manado. Jurnal EMBA, 6 (3), 1778-1787

Mulyadi. (2012). Riset dan Desain Dalam Metodologi Penelitian. Jurnal Studi dan Komunikasi Media, 16 (1), 73, 2407-6015.

Purnamasari, Yulia. (2015). Pengaruh Kualitas Produk dan Harga Terhadap Kepuasan Konsumen Produk M2 Fashion Online Di Singaraja Tahun 2015. Jurnal Jurusan Pendidikan Ekonomi (JJP), 5 (1), 7.

Suhendra, Ardhi. (2016). Kajian Tingkat Kepuasan Pengguna Trans Metro Bandung Koridor 2 Menggunakan Pendekatan Importance Performance Analysis. Rekaracana Jurnal Online Institut Teknologi Nasional, 2 (2), 63. Sugiyono. 2016. Metode Penelitian Bisnis. Bandung: Alfabeta 